Forthcoming in Philosophy and Phenomenological Research

\section{Expressivism, Inferentialism, and Saving the Debate}

Matthew Chrisman

University of Edinburgh

\section{Introduction}

It is common to distinguish between theoretical and practical reasoning. For example, my partner and I are expecting the Joneses for dinner. They call to let example, my partner and I are expecting the Joneses for dinner. They call to let
us know that they're headed out the door, and we then reason as follows: "They called to let us know they're headed out the door, their trip will take about twenty minutes, so they'll be here in about twenty minutes. The quiche needs to bake for thirty minutes, we want it to be ready shortly after the Joneses arrive, they'll arrive in about twenty minutes, so we should put the quiche in the oven now." In this case, we first infer a theoretical conclusion from evidential reasons, and then we infer a practical conclusion from instrumental reasons. There is a strong tradition in philosophy that treats these as paradigms of two fundamentally different ways of reasoning. Spelling out the difference is a difficult theoretical task, but it seems clear enough from this example that theoretical and practical reasoning have different (although importantly connected) functions in our cognitive lives. Theoretical reasoning aims to expand our knowledge of how the world is. Practical reasoning aims to expand our knowledge of how to behave in the world as we know it to be.

Although this distinction between theoretical and practical reasoning is notoriously central to normative ethical theorizing, its significance has, I think, been underappreciated and misconstrued in the metaethical debate about realism. I suspect that this is the result of two aspects of that debate: (a) the realism debate has been pursued (mostly) by investigating the appropriate semantic account of ethical statements, (b) all of the prominent semantic accounts on offer, both realist and irrealist, take representation rather than inference as their master concept, which leaves the distinction between ways of reasoning as explanatorily posterior to the distinction between representational and nonrepresentational items.

Aspect (a) is not obviously beyond reproach-perhaps the reality of moral properties should be investigated by strictly metaphysical rather than semantic methods. However, for the purposes of this paper, I shall not reproach the methodological mindset that semanticizes the realism debate in metaethics. This is because it is by working within this mindset that I think we have best hope of correcting the mistake I see embodied in aspect (b) and gaining a fuller appreciation of the significance of the distinction between theoretical and practical reasoning to the realism debate. Thus, my overarching aim in this paper is to begin to explore what happens to that debate when we take inference rather than representation as our master concept in philosophical semantics. More specifically, I want to consider the fortunes of the most prominent form of irrealism-expressivism-and urge that a new form of this position, which takes the distinction between theoretical and practical reasoning (rather than the distinction between representational and nonrepresentational mental states) as basic, has the resources to address one of the main objections threatening contemporary versions of the view.

\section{What Expressivism is for}

One perspicuous way to understand the role of expressivism in metaethical debates of the past century is as a semantic solution to an epistemological and ontological problem. The epistemological and ontological problem is that sui generis ethical facts with a character of objective to-be-doneness are hard to fit into a naturalistic conception of the world and our access to it. As Blackburn puts the point, "The natural world is the world revealed by the senses, and described by the natural sciences...However we think of it ethics seems to fit badly into that world"(1998: 48). The expressivist solution to this, what we might call, problem of naturalism is best understood in contrast to its best known alternatives. One alternative is to endorse an error-theory about ethical discourse-ethical statements are like statements about witches in that in making them people erroneously presuppose the existence of something that does not exist. ${ }^{1}$ A second alternative is to deny that the problem is a problem by rejecting the naturalistic conception of the world-ethical facts are nonnatura and we have a special moral intuition by which we can know them. ${ }^{2} \mathrm{~A}$ third alternative is to argue that a proper construal of ethical facts can locate them in the natural world as a type of natural fact to which we have access-ethical facts either reduce to or just are natural facts which are in principle knowable by empirical means. ${ }^{3}$ Expressivists reject each of these solutions to the problem of naturalism, which means that they (i) affirm the legitimacy of ordinary ethical discourse (as it now stands), (ii) deny the existence of nonnatural facts, and (iii) deny that putative ethical facts are or reduce to nonethical natural facts. In doing so, the expressivist's characteristic move is to identify and reject a common

1 See Mackie (1977: ch. 1).

2 See Moore (1903) and for updated and more plausible versions of this option Shafer-Landau (2003) and Regan (2003).

3 See Lycan (1988). Boyd (1988), Brink (1986, 2001), and Sturgeon (1984) defend simila views but are more conservative about claiming the reduction of ethical properties to natural properties. 
semantic assumption of each of the three alternatives-viz. that the meaning of ethical statements should be understood in terms of the facts they represent or (on a particular way of understanding this notion) in terms of their truthconditions. So characterized, however, expressivism is a negative thesis in need of a positive answer to the following question: if the meaning of ethical statements is not to be understood in terms of what fact they represent, then how is it to be understood?

Famously, Ayer's "Emotive Theory of Value" offers a particularly audacious and stark answer to this question. He claimed that, "insofar as statements of value are significant, they are ordinary 'scientific' statements; and ...insofar as they are not scientific, they are not in the literal sense significant, but are simply expressions of emotion which can be neither true nor false"(1946: 102-103). According to Ayer, the first of these two category includes mixed statements that might be thought to express both an ethical and nonethical judgment-e.g., "You acted wrongly in stealing that money"-and derivative ethical statements that appear to express ethical judgments but are really what Ayer calls "factual classification of an action as belonging to some class of actions by which a certain moral attitude on the part of the speaker is habitually aroused"(Ibid: 21). The focus of Ayer's theory is the second more basic category, i.e. pure ethical statements which express only moral judgments. He claimed that these are not literally significant.

Even given the distinction between mixed statements and factual classifications, on the one hand, and pure ethical statements, on the other, the emotivist thesis about the meaning of ethical statements seems highly dubious; for, according to it, the statement "You acted wrongly in stealing that money" has the same significance as "You stole that money", and the statement "Stealing is wrong" has no significance at all. However, to find this highly dubious is to fail to recognize Ayer's distinction between the genus meaningful and one of its species literally significant. ${ }^{4}$ On Ayer's stipulative usage, only those statements which are analytic or in principle verifiable express propositions, and only those statements which express propositions are literally significant. 5 So, as a thesis about the meaning of ethical statements, emotivism comes to the claim that, because (pure) ethical statements (and the ethical parts of mixed statements) are not verifiable, they are meaningful in some other way than as being literal significant.

4 Compare Miller (1998).

5 To be perfectly precise, I should say that on Ayer's view only those sentences which are analytic or verifiable express propositions. This is because, on Ayer's usage, a "statement" is just whatever content is expressed by indicative sentences, whether or not they are verifiable or analytic, and a "proposition" is the content expressed by verifiable or analytic sentences.(1946: 8) I think this use of 'statement' is confusing and won't follow Ayer in it here.
Notoriously, Ayer himself offered very little explanation of the alternative sense in which he thought pure ethical statements are meaningful. It is clear that he thought that their meaning was some sort of nonrepresentational meaning, which is why he claimed that "they are pure expressions of feeling and as such do not come under the category of truth and falsehood" and they "are calculated to arouse feeling, and so to stimulate action"(Ibid.: 108). This suggests that we could explain the meaning of pure ethical statements by coordinating their use with various feelings typically conveyed and aroused. It's not that ethical statements say that the speaker has certain feelings-that would be subjectivism-rather it's that their meaning is explained indirectly in terms of the mental states they convey and evoke. Ayer, however, was skeptical about how much philosophy can add to a positive account of the meaning of pure ethical statements: "We find that ethical philosophy consists simply in saying that ethical concepts are pseudo-concepts and therefore unanalyzable"(Ibid: 112). What is important to notice here is that when we understand concepts as the most basic components of representation, then Ayer's claim makes sense as a way to deny that ethical statements have any straightforwardly representational sort of meaning.

Although some still think of expressivism as basically a variant on Ayer's emotivism, most contemporary expressivists recognize and are responsive to a deep problem in Ayer's stark approach to the semantics of ethical discourse. The problem is that ethical statements and descriptive statements manifest clear semantic similarities that Ayer's stark semantic thesis cannot account for. For instance, just like descriptive statements, ethical statements seem to be built out of subsentential components which contribute in systematic ways to the overall meaning of the statements; just like descriptive statements, ethical statements admit of systematic syntactic transformations of tense, mood, number, etc.; moreover, just like descriptive statements, ethical statements seem to be truthapt which allows them to embed in logically complex contexts and bear logical relations to other statements. ${ }^{6}$ By drawing the expressive contrast between descriptive statements and ethical statements with the claim that the former express propositions and the latter express feelings and attitudes, Ayer's account provides a powerful, albeit blunt, instrument for construing ethical statements as semantically different from descriptive statements. For that, however, his account appears to wipe out the resources needed to adequately capture the ways in which ethical and descriptive statements are semantically similar and

6 This final aspect of similarity is related to the infamous Frege-Geach problem-see Geach (1965). Certainly, one of the central motivations for modifying expressivism in the ways I go on to discuss below has been the Frege-Geach problem. Here, I will be concerned with another sort of problem that attaches directly to those modifications rather than with the issue of whether those modifications provide adequate resources for answering the Frege-Geach problem. 
thereby integrate an account of the meaning of ethical statements into a plausible general semantic theory.7

Thus, while sympathizing with Ayer's view that ethical statements are semantically different from descriptive statements in a way that provides a distinctively expressivist solution to the problem of naturalism, contemporary expressivists hold out hope for a semantic account that integrates the distinctive meaning of ethical statements into a general philosophical account of meaning in such a way that both the semantic differences and semantic similarities between descriptive and ethical statements can be explained. From the point of view of contemporary expressivists, the key to this project is to psychologize all semantic explanation by starting from the idea that all statements conventionally express mental states of some sort or other, and the mental state conventionally expressed by a statement is what confers its semantic content. Then, they seek to capture the semantic difference between ethical and descriptive statements in explicitly psychological terms.

For example, Gibbard writes, "Just as a straightforwardly factual assertion expresses a straightforwardly factual belief, so an assertion that such-and-such is rational expresses a normative judgment"(1990: 84). And later, he contrasts expressivism with the pursuit of direct definitions of normative terms writing, “The expressivists' strategy is to change the question. Don't ask directly how to define 'good'...Ask what states of mind ethical statements express"(2003: 6). Similarly, Blackburn writes,

What is needed...is not the suggestion that evaluative predicates refer to whatever properties ground the values. We need to understand the special take on those properties had by those who value them one way or another. Until we have a theory of that, we do not understand anything of ethical thought, the content of the ethical proposition, its motivational power, its authority, and the question of whether disputes involving different valuations are cognitive disputes or something else. All of these are better understood by expressivism than by the approaches considered in this chapter [response-dependent accounts and Cornell realism].(1998: 121)

And he characterizes expressivism writing, "Expressivism denies that when we assert values, we talk about our own states of mind, in actual or potential circumstances. It says that we voice our states of mind, but denies that we

7 Of course, Ayer himself was operating with a verificationist theory of meaning, and was therefore perfectly happy to dismiss the question of how ethical and descriptive statements were semantically similar as a bad question generated by a sloppy analysis of language. See Ayer (1946: 20, 31). However, in our post-positivistic period, this stance towards understanding the meaning of ethical tatements seems, to put it charitably, under-motivated. thereby describe them"(Ibid.: 50). Thus, expressivism is characterized as an "indirect" account of the meaning of terms. Here's Gibbard again: "The term 'expressivism' I mean to cover any account of meanings that follows this indirect path: to explain the meaning of a term, explain what states of mind the term can be used to express"(2003: 7). And although Gibbard identifies this approach with expressivism, notice that it is perfectly general and does not have anything specifically to do with metaethics; it is a familiar idea from the genera psychologistic approaches to semantics that seek to explain the meaning of any term by explaining what states of mind it can be used to express. ${ }^{8}$

Of course, for the expressivist it is important that ethical statements be thought to express an importantly different kind of mental state than that expressed by descriptive statements. For example, Blackburn writes,

The theory I want to defend is one that gives a story about the way in which ethical thought functions. Valuing something, it says, is not to be understood as describing certain terms, any more than hoping for or desiring something are describing it in particular terms. Rather, the state of mind of one who values something is distinctive, but nevertheless it is itself a natural, and naturally describable, state.(1998: 49)

And Gibbard writes,

At the outset, in any expressivist's scheme, the initial states of mind are explained not as beliefs with such-and-such content, but in some other way. They are explained psychologically, as sentiments or attitudes, perhaps, or as universal preferences, states of normacceptance-or states of planning.(2003: 180-181)

From this perspective, Ayer's mistake seems to have been, in effect, to think that ethical statements express their contents in a completely different way than descriptive statements express their semantic contents. Rather than mark a representational-nonrepresentational divide by holding that the meaning of descriptive statements can be explained directly in terms of the propositions they express, while the meaning of ethical statements should be explained in terms of the feelings and attitudes they express, contemporary expressivists seek to reconstitute the representational-nonrepresentational divide in wholly psychological terms. The idea is to say that both descriptive and ethica statements express mental states responsible for the meaning of the statements; it's just that descriptive statements express a genuinely representational sort of mental state while ethical statements express some nonrepresentational sort of mental state. As I see things, the key dialectical advantage of this move is that it

\footnotetext{
8 Compare Grice (1989), Schiffer (1974), Blackburn (1984), Davis (2003).
} 
allows expressivists to distance themselves from the untoward implications of Ayer's emotivism. They are no longer forced to construe ethical statements as not propositional or not significant. Of course, they then owe us an alternative account of the meaning of ethical statements, but they have a philosophical tradition tracing back to Locke and the rich field of psychological concepts and distinctions at their disposal.

However, whatever the precise account of the mental state expressed by ethical statements is, it seems that expressivists will have to say that it has a lot of the same semantic properties as a belief. For, given expressivists' fully psychologistic approach to semantics, this will be the only way to capture the semantic similarities between descriptive and ethical statements. This is why the quote from Gibbard continues,

The expressivist then tries to show that these states of mind act much like beliefs: it is as if they were beliefs with a special kind of content. Some expressivists at the point debunk; the story, they say, shows why these seeming beliefs are mere pseudo-beliefs. A quasirealist like me stresses the vast extent of the parallel between normative convictions, as they emerge in the theory, and the plainest cases of belief in realistic content.(Ibid: 181 )

\section{Quasi-Realism, Creeping Minimalism, and Dreier's Proposa}

The badge "quasi-realist" that Gibbard here takes for his position deserves elucidation. As we saw, emotivists like Ayer hold that ethical statements are not truth-apt. And, at one point Gibbard too held this view. About the expressivist view of ascriptions of rationality defended in his first book, he writes, "The analysis is non-cognitivistic in the narrow sense that, according to it, to call a thing rational is not to state a matter of fact, either truly or falsely"(1990:8). However, this feature of the traditional expressivist view has received much appropriate critical attention over the years. For, whatever plausibility traditional expressivism gains by providing a semantic solution to the problem of naturalism it seems to lose by disrespecting the surface phenomena of ordinary ethical discourse, since it is just as easy to moralize with the statement, "Invading Iraq was wrong" as with the statement, "It's true that invading Iraq was wrong." It seems, therefore, that traditional expressivism is able to affirm the legitimacy of only part of ordinary ethical discourse; it must be implicitly committed to an error-theory about the ordinary use of the truth-predicate in conjunction with ethical statements. Because of this internal tension in traditional expressivism and as part of their attempt to integrate an expressivist account of the meaning of ethical sentences into a general semantic account, contemporary expressivists have sought to divide (i) the claim that ethical statements do not express propositions and are thus not truth-apt, from (ii) the claim that the meaning of ethical statements is to be given by showing how the psychological state they can be used to express differs from the psychological state descriptive sentences can be used to express.

Now expressivists, such as Blackburn and Gibbard, want to deny (i) while affirming (ii), and their strategy for doing so is to adopt some form of minimalism about the semantic terms 'truth' and 'proposition'. This is, roughly, the view that the phrase 'the proposition that' is just a grammatical device that we use to form noun-phrases out of indicative sentences, so all instances of the schema:

'S' expresses the proposition that- $S$,

where an indicative sentence is substituted for $S$, are true. And the phrase is true' is just a grammatical device that we use to form a sentence out of a name for a proposition, so all instances of the schema:

'P' is true iff $P$,

where $P$ can be any proposition, which, given minimalism about propositions, means that any indicative sentence can be substituted for $P .{ }^{9}$

This combination of the expressivist approach to the semantics of ethical discourse with minimalism about truth and proposition is the beginning of what Blackburn and (following him) Gibbard have called "quasi-realism". ${ }^{10}$ The adoption of minimalism lets quasi-realists recognize as legitimate-in a way that Ayer couldn't-the use of the terms 'proposition' and 'true' in ordinary ethical discourse. However, quasi-realists maintain with Ayer that there is a psychological difference in what kind of mental state ethical and descriptive statements can be used to express.

It is crucial for understanding the dialectical liabilities of quasi-realism to notice that this psychological difference can be no merely pragmatic matter. Many sorts of statements can be differentiated in terms of what type of mental state they express. For example, first-personal avowals of emotions-e.g. "I love you"-express the relevant emotion, and simple requests-e.g. "I'd like eggs"express desires, but that does not imply that we should treat them semantically as nonrepresentational. ${ }^{11}$ So for expressivism to continue to bear on the

9 Similar remarks apply to notions such as 'reference' and 'fact', but I shall leave these implici in what follows. For more direct defenses of minimalism see especially Field (1986), Horwich (1990), and Wright (1992).

11 Of course, on some deflationary accounts of self-knowledge such avowals are treated as nonrepresentational, but $I$ think these accounts are making the same mistake as would be made by an expressivist who inferred from the mere fact that ethical statements express attitudes that ethical
claims are nonrepresentational. See Bar-On (2004: 226-284) for more discussion of simple 
epistemological and ontological problem of naturalism, it has to treat the psychological difference in what kind of mental state ethical and descriptive statements can be used to express as making the crucial semantic difference between ethical and descriptive statements. ${ }^{12}$

What does "the crucial semantic difference" mean? It cannot mean just any semantic difference. For surely an ethical statement such as "Magnanimity is good" is semantically different from a descriptive statement such as "The sky is blue" in that these statements mobilize different kinds of concepts-ethical concepts and color concepts. However, that semantic difference does not by itself help with the problem of naturalism, since another uncontroversially descriptive statement such as "The road is icy" mobilizes another kind of concept still-a road condition concept-without implying anything about the ontological commitments of road condition discourse vis-à-vis color discourse. The relevant difference must be, it seems, something like the difference between psychological states that purport to represent the world and those that do not. However, the quasi-realists' ability to cogently appeal to that distinction has begun to seem problematic, and with this, the very intelligibility of the metaethical debate about realism has begun to seem problematic. ${ }^{13}$

The problem is in containing the imperialistic tendencies of minimalism. Quasi-realists endorse minimalism about 'truth' and 'proposition' in order to avoid the untoward implications of Ayer's emotivism. Initially, this forces us to recast the realism-irrealism debate in psychological terms: realists hold that ethical statements express beliefs and some of those beliefs are true. Irrealists deny that ethical statements express beliefs (although, as quasi-realists, they will now admit that some ethical statements are true, in a minimalist sense of

expressivist accounts of avowals and argument against this inference. See Dreier (1990), Copp (2001), Barker (2000), and Finlay $(2004,2005)$ for views that treat ethical statements as expressing attitudes but construe this as part of the pragmatics of ethical statements rather than the semantics.

12 Thus, I think it is no innocent move for Gibbard (2003) to start with a distinction in terms of pragmatic force between factual and plan-laden statements-i.e. a distinction in what one is doing writes "In a different and more traditionl sense, one could treat belief that I am about to pack and a decision to pack as having the same 'content', that I will forthwith pack, toward which I take different propositional attitudes: belief, and deciding to actualize. The two attitudes have different "directions of propositional attitudes: belief, and deciding to actualize. The two attitudes have different "directions of
fit". We can say, towards the same item of 'content'. Here, though, I am opting to transmute force into content: I speak of a single attitude 'accepting' that one can take towards distinct items of content, that I will forthwith pack and the plan to pack"(2003: 47) He goes on to claim that his idiosyncratic use of 'content' is optional, but what is not optional for the expressivist is that the pragmatic-psychological distinction between ethical and descriptive statements make the right sort of semantic difference in one's account of the meaning of those statements.

13 This problem has been most forcefully articulated in Dreier (2004), and following three paragraphs draw heavily on his way of pressing the issue. 'true'). ${ }^{14}$ However, the main reason for quasi-realists to adopt minimalism about 'true' and 'proposition' was to show how they can capture the aspects of ordinary ethical discourse that tempt people to reject Ayer's emotivist irrealism in favor of realism. ${ }^{15}$ But if that is the theoretical motivation for adopting minimalism about 'truth' and 'proposition', it is not clear how casting the debate in wholly psychological terms is any more friendly to expressivistic irrealism. For it is also a feature of ordinary ethical discourse to say things such as "I believe that torture is always wrong." Moreover, as Divers and Miller have stressed in this context, two apparent platitudes connect truth-evaluability to the expression of beliefs-viz., a truth-evaluable statement is an assertion, and an assertion is the expression of a belief.(1994: 14-15) ${ }^{16}$ So, if the expressivist uses minimalism about truth to win the right to view ethical statements truth-evaluable, then it seems forced on him to view ethical statements as assertions and, in turn, the expression of beliefs.

There is a response available, but it is dangerous. Minimalism about 'belief would say that there is nothing more to a statement's expressing a belief than its being an assertion, and there is nothing more to a statement's being an assertion than its being truth-apt. Quasi-realists can also "go minimalist" about 'belief' in order to capture the psychological features of ordinary ethical discourse that still tempt towards realism even once the debate is cast in wholly psychological terms. But in so doing they seem to lose the debate. For now they are forced to say that ethical statements express beliefs (minimalistically construed), which leaves it questionable what distinguishes them from realists. This is why Dreier claims that, "Minimalism sucks the substance out of heavy-duty metaphysical concept. If successful, it can help Expressivism recapture the ordinary realist language of ethics. But in so doing it also threatens to make irrealism indistinguishable from realism"(2004: 26).

As Dreier notes, some philosophers have reacted to this problem by trying to recast the realism-irrealism debate wholly within the psychological category of (minimalist) belief. That is they want to allow that both descriptive and ethical statements express beliefs, but they hold that the former statements express

14 Another way to be an irrealist is to follow the realist in holding that ethical statements follow and focus on versions of expressivism.

15 Indeed, given Ayer's own proto-minimalist account of truth, even he should have held that ethical sentences are truth-apt. He writes, "Reverting to the analysis of truth, we find that in all sentences of the form 'p is true,' the phrase 'is true' is logically superfluous....we conclude, then, that there is no problem of truth as it is ordinarily conceived. The traditional conception of truth as a 'real quality' or 'real relation' is due, like most philosophical mistakes, to a failure to analyse sentences correctly"(1946: 88-89; quoted in Dreier 2004: 24).

16 Compare also Wright (1992: 14) 
representational beliefs while the latter statements express nonrepresentational beliefs. ${ }^{17}$ But founding one's expressivist irrealism on this distinction is apt to seem folly given the momentum of minimalism's imperialistic tendencies. For, as Dreier claims, "there is plainly an ordinary sense of 'representation' that applies full well to moral beliefs"(2004: 29), which is a reflection of the analytic connections between truth-aptness, assertion, belief, and representation. So, if it is really important to the plausibility of expressivism that it capture the apparently realist-sounding surface phenomena of moral discourse, then it appears that expressivists should adopt minimalist approaches to these alternative ways of making out the necessary distinction. So, pressure to accommodate the surface phenomena of ordinary moral discourse, which has encouraged expressivists to adopt minimalism about 'truth' and 'proposition', continues to put pressure on quasi-realistic versions of expressivism that seek to mark out the relevant distinction with notions like 'belief', 'descriptive', or 'represents'. This is what Dreier calls the problem of creeping minimalism: "Once minimalism gets creeping, it's hard to see how to stop it"(2004: 29).18

But, as a form of expressivism, quasi-realism seems to be proposed as the best possible irrealist position. If it turns out to be indistinguishable from forms of realism, then the expressivist has again lost the debate. Now, at this point in the discussion, an expressivist irrealist might grant Dreier's point that, when the realism-irrealism distinction is couched in terms deployed as part of the surface phenomena of ordinary ethical discourse, ordinary ethical discourse implicitly endorses realism. But the expressivist could nonetheless insist that it remains possible to couch the distinction in terms that clearly are not deployed as part of the surface phenomena of ordinary ethical discourse. This would undermine the dialectical force of the putatively realist-sounding aspects of ordinary ethical discourse, and there would then be no pressure to let minimalism undermine the distinction between realism and irrealism.

17 Compare Timmons (1999).

18 Teemu Toppinen has suggested to me that there is a distinction that can be made between conforms to the platitudes connecting belief to truth "robust belief" - where the former is whatever to the platitudes emerging from a belief-desire psychology of action. If this distinction can hold up against minimalism, then the expressivist could claim that ordinary ascriptions of moral beliefs against minimalism, then the expressivist could claim that ordinary ascriptions of moral beliefs
require the mental state expressed by ethical claims to be only a minimal belief, while what require the mental state expressed by ethical claims to be only a minimal belief, while what
distinguishes them from realists is that they deny that ethical statements express robust beliefs. However, I doubt that there are "platitudes" emerging from belief-desire psychology of action, and, even if there are, it is far from clear that ordinary discourse doesn't implicitly treat the mental state expressed by ethical statements as what Toppinen is calling a robust belief. For notice that it is often an acceptable way to explain why someone did what she did-e.g. quit her job-by appealing to her belief that doing so was the right thing to do.
In fact, this seems to be the strategy explicitly pursued by Gibbard (2003). He stipulates technical meanings for the phrases "the thing to do" and "planladen", writing:

Suppose, let me stipulate, the phrase works like this: to conclude, say, that fleeing the building is the thing to do just is to conclude what to do, to settle on fleeing the building. By sheer stipulation then, the meaning of this phrase 'the thing to do' is explained expressivistically: if I assert "Fleeing is the thing to do", I thereby express a state of mind, deciding to flee.(2003: 15)

Why is "deciding to flee" counted as a "state of mind"? Since Gibbard pursues a psychologistic semantics and wants ultimately to explain the meaning of ethica statements in terms of the states of mind they express, this conclusion about what to do has to be a state of mind to play the necessary role in his semantics. Indeed, with the help of minimalism, this state of mind ultimately comes to be called a belief in Gibbard's theory, but it is a "plan-laden" belief which distinguishes it from a "prosaically factual" belief.(Ibid.: 7, 185-188) Thus, in Gibbard's view, the crucial semantic difference between descriptive and ethical statements is the type of belief they express-plan-laden or prosaically factual. This is a technical psychological distinction, but it is supposed to track a real distinction between kinds of beliefs that can be put to service in explaining the semantic difference between descriptive statements and ethical statements. And, initially, it is hard to see how minimalism could creep in and undermine it, since it is unclear what it would even mean to take up a minimalist approach towards the distinction between plan-laden and prosaically factual beliefs. I guess one could insist that all beliefs are prosaically factual, but there would be no pressure from ordinary ethical discourse to do so. ${ }^{19}$

I think Gibbard's move here is definitely a step in the right direction for saving the realism-irrealism debate. However, one might reasonably wonder whether Gibbard's view-with its adoption of minimalism and psychological distinction made in technical terms-continues to be a recognizably expressivistic solution to the problem of naturalism. How, that is, does the view that ethical claims express plan-laden beliefs make out room for (i) affirming the legitimacy of ordinary ethical discourse (as it now stands), while (ii) denying the existence of nonnatural ethical facts, and (iii) denying that ethical facts are or otherwise can be reduced to natural facts? To put the worry a different way:

19 Compare also the alternative proposal in Ridge (forthcoming) where he distinguishes between beliefs in the sense of whatever causally regulates ordinary use of the word 'belief' (i.e. menta states expressed by assertions) and beliefs in the sense of the natural-psychological kind of mental state posited by a mature cognitive science. He thinks that the former category includes the latter as a proper subset, and the mental state expressed by ethical claims is not purely a belief of the latter category. 
what if the realist says that he agrees with Gibbard-ethical beliefs are planladen, which he takes to mean that they represent certain actions as being the actions we should engage in? Would this be an incoherent form of realism? It doesn't seem so, and because of this, it is not clear that it constitutes a rejection of realism to say that the beliefs expressed by ethical statements are plan-laden. This is a reflection of something that we have already learned: It is not enough just to characterize the psychological nature of ethical beliefs and then just say that the beliefs expressed by uncontroversially descriptive statements are semantically different; after all, beliefs about road conditions are semantically different from beliefs about colors, which are, in turn, semantically different from beliefs about good and bad character traits. In order to offer an expressivist solution to the problem of naturalism, one needs to go further and say why the putative difference between plan-laden beliefs and prosaically factual beliefs makes a difference to the epistemological and ontological status of ethical discourse. Otherwise, one has not saved the debate.

Dreier attempts a tentative answer to this challenge on Gibbard's behalf. ${ }^{20}$ He articulates his proposal as an interpretation of Gibbard's suggestion that, "To explain belief in natural fact adequately, we must assume a natural world of which we are a part. We must start with a realm of naturalistic facts. To explain belief in normative facts, in contrast, we need not start with a realm of normative facts..."(2003: 183). It is important to note that Gibbard is not talking about what explains why a true belief is true; he wants his account of the kind of mental state expressed by ethical statements to apply both to true and false ethical statements. This is in part why Dreier interprets Gibbard's notion of 'explanation' along the lines of Fine (2001) writing: "The explanation of your belief that the moon is a quarter of a million miles away, in this context, is that in virtue of which it is true to say of you that you believe it. And Gibbard is speculating that an account of what naturalistic belief consists in will appeal to naturalistic facts"(2004: 38). And he could have added: on this interpretation, Gibbard's view is that an adequate account of what normative belief consists in will not appeal to normative facts. Dreier calls this the "explanation" explanation of the distinction between realism and irrealism. According to it, if one thinks that the explanation of that in virtue of which one counts as having a normative belief requires appeal to normative facts, then one is a normative realist, otherwise, one is a normative irrealist.

However, it is not immediately clear what it means to appeal to certain kinds of facts in the explanation of that in virtue of which one counts as having certain kinds of beliefs. Are the facts appealed to the ones believed in? Dreier

20 Dreier (2004:: 32-39) drawing on O'Leary-Hawthorne and Price (1996), Gibbard (2003), and Fine (2001) considers the question of whether Gibbard's realism about naturalistic beliefs comes to the view that an account of what the beliefs consist in will appeal "to the very facts that are also the objects of beliefs?" He writes, "Gibbard is not specific...but I don't see why he would resist [this] suggestion”(2004: 44). However, it seems to me that Gibbard should resist this suggestion. For suppose Joey believes that the planet Krypton is made of kryptonite; clearly, neither the cosmological realist nor the cosmological irrealist will want to appeal to the fact that Krypton is made of kryptonite in explaining that in virtue of which Joey counts as having the cosmological belief that he does-for this is not really a fact. So, it cannot be true, in general, that the realist will appeal to the very facts believed in to explain that in virtue of which someone counts as having those beliefs.

But what facts, then, are the relevant facts that one must appeal to in the explanation of Joey's belief in order to count as a realist? Will the cosmological realist nonetheless appeal to other cosmological facts in explaining Joey's cosmological beliefs? I don't see why. Regarding the belief that the moon is roughly a quarter of a million miles away, Dreier writes, "...a realist about the moon should say that belief that the moon is a quarter of a million miles away consists in some fact that includes the moon, presumably the fact of standing in some representation relation to the moon"(2004: 44). However, not any relata of the representation relation will do the job here; indeed, it seems like we need it to be a representation of the fact that the moon is a quarter of a million miles away. But this won't do as a general characterization of realism. For, what about Suzy who believes that the moon is made of cheese? The realist about the moon will not want to appeal to the fact that Suzy stands in the representation relation to the fact that the moon is made of cheese, since this is not a fact. There is no fact that the moon is made of cheese to which Suzy can stand in a representation relation. So appeal to such a (putative) fact cannot be part of the best explanation of that in virtue of which Suzy counts as believing in what she does about the moon.

What we seem to need here is the fact that Suzy represents the moon as being made of cheese and the fact that Joey represents Krypton as being made of kryptonite and the fact that we represent the moon as being roughly a quarter of a million miles away. These are all facts that one might appeal to in explaining that in virtue of which Suzy, Joey, and we have the relevant cosmological beliefs. And, if this is a mark of realism, then the normative realist would say that the normative belief, e.g., that stealing is wrong is explained by the fact that the believer represents stealing as wrong, while the irrealist would give some other explanation (perhaps, that the believer has adopted a plan not to steal). 
With this, however, we seem to be back to conceiving of the distinction between realism and irrealism in terms of the distinction between representational and nonrepresentational mental states. And that surely spells trouble for Dreier's proposal, since he has already shown us what is wrong with using 'representation' as a way to distinguish expressivists from realists: it is open to the imperialistic aspirations of creeping minimalism.

\section{An Inferentialist Alternative}

So far, we have seen that expressivists want to articulate a distinction between what ethical statements express and what uncontroversially descriptive claims express, and this distinction must be is serviceable in a response to the problem of naturalism. Contemporary expressivists seek to do this in psychological terms, where the leading idea is to treat descriptive statements as expressive of representational mental states and ethical statements as expressive of some other nonrepresentational kind of mental state. However, when it comes to trying to articulate this distinction between representational and nonrepresentational mental states, the ordinary psychological terms 'belief/attitude won't help because they render expressivism implausible or the distinction is vulnerable to creeping minimalism. And trying to make the distinction in technical psychological terms a la Gibbard doesn't seem to help either, since it renders the distinction either conceptually independent of the problem of naturalism or, as we saw in the discussion of Dreier's proposal, it implicitly depends on a distinction made in a way ultimately vulnerable to creeping minimalism. Do these failures mean that we should return to the semantic assumption implicit in the three original rivals to expressivism, viz. that the meaning of ethical statements is to be given in terms of which facts they represent?

In my view, to return straightaway to that assumption is to overlook a third viable avenue of general semantic explanation. This is the inferentialist approach, which seeks to explain meaning (even of uncontroversially descriptive statements) in terms of inference rather than representation. ${ }^{21}$ The inferentialist approach to semantics doesn't deny that the content of a statement is related to the content of the mental state that it conventionally expresses, but it reverses the order of explanation pursued in the psychologistic approach to semantics, which we have seen to be implicit in contemporary versions of metaethical expressivism. That is, the inferentialist approach encourages us to explain the content of mental states in terms of the content of statements that

21 Brandom (1994, 2000) offers the most worked out articulation and defense of semantic inferentialism, but he traces the approach to Frege (1879), Sellars (1948, 1968), and Dummett (1973). Compare also Rosenberg (1974) conventionally express these mental states, which in turn is explained in terms of their role in the socially-embodied inferential practice of making statements and giving and asking for reasons for these statements. So, for instance, the meaning of the statement "The moon is a roughly quarter of a million miles away" is, according to the inferentialist, constituted by its role in the practice of making statements and giving and asking for reasons. This comes, broadly speaking, to two things-(i) what circumstances license making the claim and (ii) what further statements and actions are licensed by the statement. In this case, the statement is licensed by things like testimony of an expert, the reading on a reliable measurement device, or a variety of other statements which materially imply this statement; and it licenses further statements such as "The moon is more than a hundred miles away", "The moon is less than a million miles away", etc. It is this complex of what we might call upstream and downstream inferential potential that constitutes the inferential role of the statement. And, according to semantic inferentialism, this role is basic in the explanation of the meaning of the statement.

The three-way debate between those who pursue an inferentialist approach to semantics and those who pursue a psychologistic approach and those who pursue a more direct representationalist approach cuts deep into many philosophical controversies. My purpose here is not to enter that debate but rather to accomplish two more modest tasks: (i) to point out that, even though the contemporary metaethical debate about realism has been pursued (mostly) by investigating the semantics of ethical statements, the inferentialist approach to semantics has been largely ignored in this debate; and (ii) to argue that inferentialism has something significant to add to the development of a plausible version of expressivism.

What I have to say in service of (i) is complete, so the remainder of the paper will be in service of (ii). What I think inferentialism has to offer here is the resources for a new form of expressivism that doesn't fall prey to the problem of creeping minimalism. The key is what we started with-viz. the distinction between theoretical and practical reasoning. With both sorts of reasoning, one makes inferences by moving from premises to a conclusion; however, since the functions of these ways of reasoning in our cognitive lives are recognizably different, the proper relationship between the premises and the conclusion for each type of inference is also different. Generically, the premises of a theoretical inference should provide evidential support for the conclusion. When they do so adequately and one is committed to them, that is good theoretical reason to be committed to the conclusion. And when the conclusion is true, such a commitment will usually constitute theoretical knowledge about the world. By contrast, the premises of a practical inference should provide practical support 
for the conclusion. When they do so and one is committed to the premises, that is good practical reason to be committed to the conclusion. And when the conclusion is true, such a commitment can constitute practical knowledge about how to interact with the world as we know it to be.

What is crucial here is that, since the inferentialist thinks that the meaning of a statement is constituted by its complex inferential-role, this distinction between theoretical and practical inferences will have direct semantic implications for the meaning of different kinds of statements. More specifically, when we look at the inferential-role of various sorts of statements-which, recall, is constituted by the complex pattern of things that license the statement and things that the statement licenses-some statements will have a recognizably practical component in that they can directly license particular actions, while others will lack this component in that they always require the support of some other practical premise in order to license particular actions. Recall the example with which I began. In this example, my partner and I inferred that the Joneses would arrive in 20 minutes. But, intuitively, the statement "The Joneses will arrive in 20 minutes" doesn't license any particular action and it isn't justified by a practical inference. What we need in order to get to an action is for that statement to dovetail with another statement with some practical inferential import. In the example, what happened was that we reasoned further from the desire to have the quiche ready shortly after the Joneses arrived to the conclusion that we should put the quiche in the oven now. And, intuitively, the statement "We should put the quiche in the oven" does license a particular action, namely, putting the quiche in the oven, and it is reached by a piece of practical reasoning. Given the inferentialist approach to semantics, this means that the statement "We should put the quiche in the oven" has a recognizably practical component in its meaning: it is licensed by statements which provide it inferential support in the way of practical reasoning and it directly licenses an action. ${ }^{22}$

Articulating the fine structure of the inferential relations between various statements is no easy task, but the important point here is that, given the intuitive distinction between theoretical and practical reasoning, the semantic inferentialist will have to recognize a difference between, on the one hand, statements with theoretical inferential-roles and, on the other hand, statements ${ }^{22}$ James Dreier has suggested to me that Prior's (1960) challenge to the principle that one
cannot derive an ought from an is may cause a problem for thinking of all ethical statements as expressive of distinctively practical commitments. I remain unsure what to think about Prior's counterexamples, which are somewhat peculiar counterexamples to the principle, but they at most challenge the idea that the upstream inferential potential of all ethical statements includes a practical commitment. The fact that ethical (and more generally normative) statements can license actions still distinguishes their inferential role from uncontroversially descriptive statements. with practical inferential-roles. To use the idiom of expression, we might capture this idea by saying that some statements express theoretical commitments, while other statements express practical commitments-where the idea of expressing a commitment is used not to refer (directly) to the mental state conventionally conveyed by a statement but to the inferentially articulated place in the practice of making statements and giving and asking for reasons taken up by one who makes the statement.

This distinction between statements which express theoretical commitments and statements which express practical commitments is a wholly general implication of the inferentialist approach to semantics combined with recognition of the intuitive distinction between theoretical and practical reasoning. But its specific application to the metaethical debate discussed above is perhaps already coming into view.

In that debate, expressivists sought to articulate an expressive contrast between ethical statements and uncontroversially descriptive statements, where this contrast needed to make a difference to the expressivist's distinctive solution to the ontological and epistemological problem of naturalism. Ayer attempted this in a crude way: in effect, he treated descriptive statements and ethical statements as standing in different sorts of expression relations to their meanings. For Ayer, descriptive statements express propositions (i.e. truthevaluable contents), and ethical statements express feelings or attitudes but not propositions. As we saw, this seems to make the semantic explanation of ethical statements too different from the semantic explanation of descriptive statements to plausibly capture the apparent semantic similarities. This is why most contemporary expressivists have attempted to draw the distinction entirely in psychological terms: both descriptive and ethical statements express mental states, but the types of mental state expressed are different. This is more promising, but the various versions that have been proposed are, as we saw, threatened by minimalism's tendency to undermine the realism-irrealism debate.

Semantic inferentialism provides a new way to cast the realism-irrealism debate that, I think, leaves room for a plausible expressivist position within that debate. The distinction between theoretical and practical commitments was defined in terms of a distinction between types of inferential-roles-theoretical and practical-which, in turn, is a matter of the distinction between theoretical and practical reasoning. Since theoretical reasoning aims to increase our knowledge about the world, theoretical commitments can be seen as commitments about what reality is like. And, since practical reasoning aims to increase our knowledge about how to interact with the world as we know it to be, practical commitments can be seen as commitments about how to act, which 
contrasts them with theoretical commitments. This underwrites the following way of construing the metaethical debate about realism: Ethical realism is the position that ethical statements express theoretical commitments and some of them are true. Irrealism is the denial of this conjunction. So, this conception of the debate leaves room for an error-theoretic form of irrealism, which says that ethical statements express theoretical commitments but none of the positive ethical statements are true. And, more importantly, there is also room for an expressivist form of irrealism, which says that ethical statements are semantically different from uncontroversially descriptive statements precisely in that they express practical commitments rather than theoretical commitments.

This form of expressivism says that both descriptive statements and ethical statements express commitments-i.e. have inferential roles-but then distinguishes between what each kind of statement expresses in entirely in inferential terms. The fact that they both express commitments is the first step in capturing the apparent semantic similarities between descriptive and ethical statements, while the distinction between theoretical and practical reasoning allows us to articulate a new expressive contrast-viz., descriptive statements express theoretical commitments, while ethical statements express practical commitments. We might call this an inferentialist version of expressivism to distinguish it from previous psychologistic versions of expressivism.

To fully flesh out and defend an inferentialist version of expressivism, one would need to explore the fine-structure of the inferentially articulated commitments expressed by ethical statements. This is a parallel but different task from the attempt by defenders of psychologistic versions of expressivism to explore the fine-structure of the psychologically embodied mental states expressed by ethical statements. Unlike the latter task, the former task doesn't require us to locate the moral belief in syndrome of psychological causes of action $^{23}$ but rather to locate the moral commitment in a syndrome of normative reasons for further commitments and actions. In either case, the project is highly speculative, but, in my view, not too speculative to be helpful for framing further investigations and articulating a metaethical view.

It is in this speculative vein that a defender of an inferentialist version of expressivism would argue that, in ordinary ethical discourse, ethical statements seem to play a distinctively practical inferential-role. We have already seen how a statement such as "We should put the quiche in the oven" seems to have a distinctively practical inferential-role. This had two parts; first, what licenses the statement must include some other distinctively practical statement, and, 23 Gibbard (1990: chapters $2,4,6,7)$ and Blackburn (1998: $2,3,5)$ pursue a roughly
functional-role approach to identifying what they see as the semantically relevant psychological state. second, what the statement can license is an action. ${ }^{24}$ Many ethical statements seem similar. Consider, for instance, "One shouldn't steal." What licenses this statement? This is a complex issue, but two things seem relatively clear. First, this statement is rarely, or even never, plausibly thought of as an observationreport. This means that its license will be other statements rather than the observation of some passing scene. Second, Moorean considerations seem to show us that this statement cannot be directly inferred from uncontroversially descriptive statements such as "I desire to desire not to steal" or "Stealing doesn't maximize utility". We seem to need some higher-order normative statement to justify the statement "One shouldn't steal." And, what does this statement license? This too is a complex issue, but it seems relatively clear that this statement can license the action of refraining from stealing.

If these speculative remarks about the inferential role of "One shouldn't steal" are on the right track, then the inferentialist expressivist will insist that this ethical statement is like the statement "We should put the quiche in the oven" in that they both express practical commitments, which distinguishes them from descriptive statements, which express theoretical commitments.

\section{Conclusion and Outstanding Issues}

It is unclear how far this inferentialist expressivist line could be pushed, but we've already got an example of how it works for an obvious paradigm of an ethical statement. So rather than push it further, let me conclude by exploring the question of how inferentialist versions of expressivism are better than psychologistic versions of expressivism. A central problem with the latter views, we've seen, is that they are forced to adopt minimalism about 'truth', 'proposition', 'belief', 'representation', etc. in the quasi-realist inspired attempt to capture the features of ordinary discourse which tempt people to realism. But minimalism seems to undermine all of the ordinary terms with which the difference between expressivistic irrealism and realism is usually explained. We can try to save the debate by making a new distinction in stipulative psychological terms, but it is not clear how such stipulations really bear on the problem of naturalism or relate to the terms of ordinary discourse with which that problem is stated.

By contrast, the difference in inferential-role that the inferentialist expressivist will argue for seems to be actually manifested in ordinary ethical discourse. The statement "One shouldn't steal" is licensed by other statements standing in a practical inferential relation to this statement, and this statement

24 These parts are inferential correlates to (and thus crucially different from) the causal inputs and outputs to moral beliefs that a functional-role approach uses to identify the relevant mental state. 
license certain kinds of actions by standing in a practical inferential relation to them. This distinguishes ethical statements from uncontroversially descriptive statements such as "Stealing causes harm", since these statements are licensed by other statements standing in a theoretical inferential relation to them, and they license only other descriptive statements which stand in a theoretical inferential relation to them. By marking the expressive contrast between descriptive statements and ethical statements in inferential terms, the inferentialist expressivist is not vulnerable to creeping minimalism. For, unlike the expressivist who states the contrast with realism in terms such as 'proposition', 'truth', 'belief', or 'representation', the expressivist who states the contrast in inferential terms faces no pressure from ordinary discourse to abandon his contrast. But, importantly, this is not because the contrast is made in stipulative psychological terms. The inferentialist expressivist will grant that the contrast he seeks to draw is stated in technical terms-the idea of 'expressing a commitment' is stipulatively defined-but he will insist that the contrast is actually reflected in the ordinary practice of making statements and giving and asking for reasons. When we seek to justify ethical statements, we don't look to the world or to statements standing in a theoretical inferential relation to the ethical statement. Rather we look for a higher-order statement that stands in practical inferential relation to the ethical statement. When we seek to justify our actions, appealing to an ethical statement which stands in a practical inferential relation to the action is a good and ordinary way to do so.

At least, this is what the inferentialist expressivist will seek to show by articulating the relevant parts of the fine structure of the practice of making statements and giving and asking for reasons. I don't take this speculative task to have been fully executed here. So, perhaps I should state my conclusion in the form of a proposal. What I have done here is to show how an inferentialist approach to semantics allows for a new way of drawing the realism-irrealism contrast in metaethics, which, in turn, allows for a new inferentialist version of metaethical expressivism. The view is that ethical statements express inferentially articulable practical commitments, and this distinguishes them from descriptive statements which express inferentially articulable theoretical commitments. Initial consideration of the dynamics of the part of the practice of making statements and giving and asking for reasons in which ethical statements are located appears to support this contrast; however, for all I have said here, it could turn out that inferentialist expressivism is wrong. What is important for my modest aspirations here is that, since the contrast between theoretical and practical commitments is not made in terms that are threatened by creeping minimalism, it provides a new way to approach the question of realism in metaethics. The idea is to investigate further whether ethical statements truly do express practical commitments as the inferentialist expressivist supposes or theoretical commitments as the realist supposes. By framing this question inferentially, we save the debate and, I think, hope for expressivists who want to adopt some form of minimalism as a way to capture the features of ordinary ethical discourse that tempt some to realism. ${ }^{25}$

\section{BIBLIOGRAPHY}

Ayer, A. J. (1946) Language, Truth and Logic, $2^{\text {nd }}$ edition, Victor Gollancz, Ltd., London.

Bar-On, Dorit. (2004) Speaking My Mind: Expression and Self-Knowledge, Clarendon University Press, New York.

Barker, Stephen. (2000) "Is Value Content a Component of Conventional Implicature?" Analysis, 60: 268-279.

Blackburn, Simon. (1984) Spreading the Word, Oxford University Press, New York. Press, New York

(1993) Essays in Quasi-Realism, Oxford University York.

Boyd, Richard. (1988) "How to Be a Moral Realist” in Sayre-McCord, ed. Essays on Moral Realism, Cornell University Press, Ithaca.

Brink, David, O. (1989) Moral Realism and the Foundation of Ethics, Cambridge University Press, Cambridge.

Brandom, Robert. (1994) Making It Explicit, Harvard University Press, Cambridge. Cambridge.

(2000) Articulating Reasons, Harvard University Press,

Copp, David. (2001) "Realist-Expressivism: A Neglected Option for Moral Realism," Social Philosophy and Policy, 18: 1-43.

Davis, Wayne. (2003) Meaning, Expression, and Thought, Cambridge University Press, Cambridge.

\footnotetext{
${ }^{25}$ I would like to thank James Dreier, Michael Ridge, and Teemu Toppinen for helpful comments on earlie
} versions of this paper. 
Divers, John, and Alexander Miller. (1994) "Why Expressivists about Value Should not Love Minimalism about Truth" Analysis 54: 12-19.

Dreier, James. (1990) "Internalism and Speaker Relativism," Ethics, 101: 6-26.

. (2004) "Meta-Ethics and the Problem of Creeping Minimalism" Philosophical Perspectives, 18: 23-44.

Dummett, Michael. (1973) Frege's Philosophy of Language, Harper and Row, New York.

Field, Hartry. (1986) "The Deflationary Conception of Truth" in MacDonald and Wright, eds. Fact, Science and Morality, Blackwell, Oxford.

Finlay, Stephen. (2005) "Value and Implicature," Philosophers' Imprint, vol. 5, no. 4: 1-20 <www.philosophersimprint.org/005004/>. . (2004) "The Conversational Practicality of Value Judgements," The Journal of Ethics, 8: 205-223.

Fine, Kit. (2001) “The Question of Realism” Philosophers' Imprint, vol. 1, no. 1:1-30 <www.philosophersimprint.org/oo1001/>.

Frege, Gottlieb. (1879) Begriffsschrift, selections reprinted in Beaney, Michael, ed. (1997) The Frege Reader, Blackwell Publishers, Oxford.

Geach, Peter. (1965) “Assertion,” The Philosophical Review, 74: 449-465.

Grice, H. P. (1989) Studies in the Way of Words, Harvard University Press, Cambridge.

Gibbard, Allan. (1990) Apt Feelings, Wise Choices, Harvard University Press, Cambridge. Cambridge.

(2003) Thinking How to Live, Harvard University Press,

Horwich, Paul. (1990) Truth, Basil Blackwell, Oxford.

Lycan, William, G. (1988) Judgment and Justification, Cambridge University Press, Cambridge.

Mackie, J. L. (1977) Ethics: Inventing Right and Wrong, Penguin, New York.

Miller, Alexander. (1998) "Emotivism and the Verification Principle', Proceedings of the Aristotelian Society, vol. 98: 103-124.

Moore, G. E. (1903) Principia Ethica, Cambridge University Press, Cambridge.

O'Leary-Hawthorne, John and Huw Price. (1996) "How to Stand Up for NonCognitivists", Australasian Journal of Philosophy: 74: 275-293.

Prior, A. N. (1960) "The Autonomy of Ethics," Australasian Journal of Philosophy, 38: 199 - 206.
Ridge, Michael. (forthcoming) "The Truth in Ecumenical Expressivism", in David Sobel, ed. Reasons for Action, Cambridge University Press, Cambridge.

Rosenberg, Jay. (1974) Linguistic Representation, D. Reidel Publishing Co.; Dordrecht, Holland.

Sellars, Wilfrid. (1948/1980) "Inference and Meaning" reprinted in Pure Pragmatics and Possible Worlds, Sicha, ed., Ridgeview Publishing Co., Ridgeview.

(1968) Science and Metaphysics: Variations on Kantian Themes, Routledge \& Kegan Paul, London.

Schiffer, Stephen. (1972) Meaning, Clarendon Press, Oxford.

Shafer-Landau, Russ. (2003) Moral Realism: A Defense, Oxford University Press, New York

Sturgeon, Nicholas. (1984) "Moral Explanations" in Copp and Zimmerman, eds. Morality, Reason, and Truth, Rowman \& Littlefield, Totowa.

Timmons, Mark. (1999) Morality Without Foundations, Oxford University Press, New York.

Wright, Crispin. (1992) Truth and Objectivity, Harvard University Press, Cambridge. 